\title{
Life Satisfaction, Affects at School and Depression Symptoms among Adolescents
}

\author{
João Lucas Dias-Viana ${ }^{1}$ (iD \\ Ana Paula Porto Noronha ${ }^{1}$
}

\begin{abstract}
The literature indicates that life satisfaction has a direct effect on depression symptoms. For better understanding depression in adolescence, this research examined the relation between life satisfaction and depression symptoms among Brazilian adolescents, and verified the direct effects of positive and negative affects at school, in addition to the mediating effect of these variables on the relation between life satisfaction and depression symptoms. A total of 428 adolescents participated in the research, with mean age equal to 14.88. The Baptista Depression Scale, the Life Satisfaction Scale, and the School Subjective Well-being Scale were used. The models were tested using Path Analysis. The results indicated that affects at school mediated the relation between life satisfaction and depression symptoms. Prevention initiatives that consider the affects related to the school context can be a useful strategy for the promotion of youth mental health.
\end{abstract}

Keywords: psychological assessment, adolescents, depression, emotional states, mental health

\section{Satisfação com a Vida, Afetos na Escola e Sintomas Depressivos em Adolescentes}

\begin{abstract}
Resumo: A literatura indica que satisfação com a vida possui efeito direto em sintomas depressivos. Para melhor compreensão da depressão na adolescência, esta pesquisa teve como objetivo examinar a relação entre satisfação com a vida e sintomas depressivos em adolescentes brasileiros, e verificou os efeitos diretos dos afetos positivos e negativos na escola, bem como o efeito mediador destas variáveis na relação entre satisfação com a vida e sintomas depressivos. Participaram da pesquisa 428 adolescentes, com média de idade igual a 14,88. Foram utilizadas Escala Baptista de Depressão, Escala Global de Satisfação com a Vida e Escala de Bem-Estar Subjetivo Escolar. O teste dos modelos foi feito por meio de Path Analysis. Os resultados indicaram que os afetos na escola mediaram a relação entre satisfação com a vida e sintomas depressivos. Iniciativas de prevenção que considerem os afetos relacionados ao contexto escolar podem ser uma estratégia útil para promoção da saúde mental de jovens.
\end{abstract}

Palavras-chave: avaliação psicológica, adolescentes, depressão, estados emocionais, saúde mental

\section{Satisfacción con la Vida, Afectos en la Escuela y Síntomas Depresivos en Adolescentes}

\begin{abstract}
Resumen: La literatura indica que la satisfacción con la vida influye directamente en síntomas depresivos. Para una mejor comprensión de la depresión en la adolescencia, esta investigación examinó la relación entre la satisfacción con la vida y los síntomas depresivos en adolescentes brasileños, y verificó los efectos directos de los afectos positivos y negativos en la escuela, así como el efecto mediador de estas variables en la relación entre la satisfacción con la vida y los síntomas depresivos. Participaron en la investigación 428 adolescentes, con edad media igual a 14,88. Se utilizaron la Escala Baptista de Depresión, la Escala de Satisfacción de Vida y la Escala de Bienestar Escolar Subjetivo. Los modelos se probaron utilizando Path Analysis. Los resultados indicaron que los afectos en la escuela mediaron la relación entre la satisfacción con la vida y los síntomas depresivos. Las iniciativas de prevención que tengan en cuenta las afecciones relacionadas con el contexto escolar pueden ser una estrategia útil para promover salud mental de jóvenes.
\end{abstract}

Palabras clave: evaluación psicológica, adolescentes, depresión, estados emocionales, salud mental

${ }^{1}$ Universidade São Francisco, Campinas-SP, Brazil.

Correspondence address: João Lucas Dias Viana. Universidade São Francisco. R. Waldemar César da Silveira, 105 Jardim Cura D’Ars (SWIFT), Campinas-SP, Brazil. CEP 13.045-510 E-mail: jolucasviana@gmail.com
Adolescence represents a stage of development characterized by numerous biological, cognitive, and psychological changes. During this stage of development, social determinants, such as family context, school setting, community, relationship established with peers, and culture 
may function as risk and/or protective factors for youth mental health (Bernaras, Jaureguizar, \& Garaigordobil, 2019). Youth subjective well-being indicators are important variables for the promotion of mental health (Baptista, Hauck Filho, \& Cardoso, 2016; Gigantesco et al., 2019). Research indicates the direct effects of life satisfaction on depressive symptoms (Lin \& Yi, 2019; Morales-Vives \& Dueñas, 2018). However, little is known as to how underlying contextual well-being variables can contribute to explain the relation between these variables. Considering school as an important context for youth development, this research aims to examine the direct effects of positive and negative affects at school, in addition to the mediating effect of these variables on the relation between life satisfaction and depressive symptoms.

According to the World Health Organization, it is estimated that 350 million people are affected by depression, a psychiatric condition that is considered a global public health problem, which is among the most prevalent nonfatal diseases, affecting not only adults, but also children and adolescents. Prevalence studies indicate that depression is the third leading cause of illness among adolescents. It is estimated that $13.4 \%$ of the youth population has some psychopathology, with depression and anxiety disorders being the most common (World Health Organization [WHO], 2017). Depression symptoms in adolescents are similar to those observed in adults: depressed mood, feelings of loneliness, despondency, sadness, irritability (negative affectivity), sleep alterations (insomnia or excessive sleep), and loss of interest in activities (American Psychiatric Association [APA], 2014).

The etiology of these symptoms is considered complex, since it involves biological components (e.g. sex, heredity, health conditions), psychological components (e.g. personality; positive personal characteristics), and contextual components (e.g. family, school, leisure, community). Each of these factors can function as risk or protective factors for youth mental health, increasing or decreasing juvenile vulnerability to behavioral and affective difficulties (Bernaras et al., 2019). Thus, it is important to identify variables that prevent the emergence and worsening of depressive symptoms in adolescents (Yang, Lau, \& Lau, 2018). The literature indicates that issues related to gender, age, adolescent pregnancy, unemployment, low parental affection, low school performance, and negative schooling experiences are risk factors for depression in adolescents ( $\mathrm{Lu}, 2019)$.

Theoretical models of children and youth mental health, for example, depressive disorders, comprehend the phenomenon through models that integrate two independent dimensions: one is more related to psychopathological symptoms and the other is related to the positive characteristics of mental functioning, which are considered protective as to mental health. These characteristics are personal resources that can be developed and are associated with the individual's ability to control, influence and be influenced by the setting. These studies demonstrate the importance of positive personal characteristics, such as subjective well-being (SWB) - composed of life satisfaction factors, positive affects and negative affects - as a variable of mental health protection against depression symptoms (Baptista et al., 2016; Caci, Morin, \& Tran, 2015; Yang et al., 2018). Accordingly, the WHO (2017) recommends the implementation of interventions to increase subjective wellbeing levels as a strategy to reduce depression symptoms. In addition, health agencies around the world have adopted SWB measures, especially life satisfaction (LS), as an indicator of mental health for the development of public policies (Gigantesco et al., 2019).

Regarding the children and youth population, research on SWB has been conducted from two perspectives: (1) the adolescent's subjective assessment of their life as a whole (SWB) and (2) assessment of the developmental context in which the adolescent is situated (e.g. school, family, community) (Diener et al., 2017). It is understood that risk factors and well-being promotion factors are present in each context adolescents are situated. With regard to the first perspective, life satisfaction is a fundamental variable for understanding children and youth SWB.

Life satisfaction is a person's subjective and cognitive assessment of their life as a whole; it refers to the level of personal contentment in relation to their own life, based on the distance between life goals already achieved and the goals to be achieved. In order to assess LS, people consider the good and bad aspects. Some prioritize pleasurable and enjoyable events, while others favor stressful events. The assessment of how satisfied one is with life expresses different pieces of information, since people are not equal and are under the influence of a multitude of factors, such as mood states, thoughts and feelings present at the moment (Diener et al., 2017).

Youth LS is negatively associated with externalizing and internalizing behaviors, such as chemical substance abuse, internetaddiction, anxiety, and depression (Zhu\& Shek, 2020). Thus, it is an important factor related to mental health. People with poor results in mental health self-assessment tend to have low levels of life satisfaction (Lombardo, Jones, Wang, Shen, \& Goldner, 2018). With regard to depression symptoms, studies conducted with Asian and European adolescents indicate a negative correlation between the variables, with high magnitude $(r=-0.51)$, in addition to LS negatively predicting depression symptoms (Lin \& Yi, 2019; Morales-Vives \& Dueñas, 2018).

As for the second perspective for research on SWB (according to the contexts of child and youth development), we note the investigation of positive affects at school (PAS) and negative affects at school (NAS). Schools constitute an important domain to consider, taking into account the total number of years of basic schooling, the amount of daily hours that the student is situated in this context, in addition to the relations that students establish with peers, with teachers, which are fundamental resources for the students' well-being (Dias-Viana \& Noronha, 2021; Huebner, 2004).

The PASs are characterized by the experience of intense and frequent pleasure events at school, in which students perceive themselves as confident, determined, 
and capable. The NASs, in turn, comprise the experience of dissatisfaction and discontentment emotions at school, in which students feel unmotivated, incapable and upset (Dias-Viana \& Noronha, 2021). Thus, the students' emotions result from schooling experiences (Robina-Ramírez, Merodio, \& McCallum, 2020). The literature shows that the adolescents' emotions at school not only contribute toward aspects related to learning, such as learning strategies and self--regulation for learning (Pekrun, 2017), but also have direct effects on youth mental health. There is evidence in the literature that positive affects in relation to life function as a protective factor for depression symptoms and promote mental health. Negative affects, in turn, are associated with depression symptoms and are risk factors for mental health (Díaz-García et al., 2020). However, there is little empirical evidence of the direct and indirect effects of affects at school on student depression and mental health.

Investigations on youth SWB, whether through global assessment or through specific contexts, have become central to the school curricula of several countries, with the aim of promoting the healthy psychological development of students (Organization for Economic Co-operation and Development [OECD], 2017). This concern stems from the fact that the indicators show the school as a competitive, oppressive and stressful setting, causing damage to the students' mental health, through feelings of anxiety, stress, loneliness, and even suicide attempts among students (Au \& Kennedy, 2018). In the Brazilian context, the last published edition of the National School Student Health Survey (Instituto Brasileiro de Geografia e Estatística [IBGE], 2016) indicated that $15.55 \%$ of adolescents aged 13 to 17 years reported that they felt alone most of the time or always in the last year; $11.4 \%$ frequently lost sleep due to concerns; and $4.4 \%$ said they did not have close friends. These data show feelings of loneliness, lack of social support, and sleep disturbances that constitute symptoms and risk factors for depression disorders (APA, 2015).

As stated above, this research aimed to examine the relation between life satisfaction and depression symptoms among Brazilian adolescents. Hypothesis 1 (H1) supports that life satisfaction presents a negative and significant relation with depression symptoms and a positive relation with mental health indicators. In addition to aspects of the individual, aspects of the setting also explain the depression symptoms and mental health of adolescents (Bernaras et al., 2019). As mentioned, school issues are risk factors for the development of depression symptoms ( $\mathrm{Lu}, 2019)$. Thus, the second objective of this research is to verify the direct effects of positive and negative affects at school, in addition to the mediating effect of these variables on the relation between life satisfaction and depression symptoms. Hypothesis 2 (H2) of this study predicts that positive and negative affects at school present a mediating effect between life satisfaction and depression symptoms. Considering that investigations on school SWB are recent, the models of this study were not tested in previous studies and highlight the importance of affects at school as a risk variable for depression symptoms in adolescence.

\section{Method}

\section{Participants}

This research has a cross-sectional design. The study included 428 adolescents, mostly female $(n=240 ; 55.30 \%)$, with ages ranging from 12 to 19 years $(M=14.88 ; S D=1.70)$, students from the 7 th grade of elementary school to the second grade of high school, regularly enrolled in a state public school (Ideb $=7.0$ ) in the municipality of Fortaleza $(\mathrm{HDI}=0.745)$, which ranks among the five best schools in Ceará according to the SAEB. The school has a library, reading room, computer and science laboratory, and an indoor sports court. Exclusion criteria for the study: students who had severe cognitive impairment and/or some disorder that prevented them from participating in the research. Information about which students met the sample exclusion criteria was obtained from the school's coordination. After consulting the school managers, no students met the exclusion criteria of this research. The number of participants in this research was estimated by consulting the data from the School Census, having as population the number of students enrolled from the 7th grade of elementary school to the third grade of high school in public schools in the State of Ceará (666,134 students). Sample calculation with a 95\% confidence level and a sampling error of 5\% indicated a minimum of 180 cases.

\section{Instruments}

Sociodemographic Identification Questionnaire. An instrument developed by the proponents of this study, consisting of eight questions, including name, age, date of birth, sex, school grade, class, shift.

Life Satisfaction. Global Life Satisfaction Scale for Adolescents - EGSV-A (Segabinazi, Zortea, \& Giacomoni, 2014). The instrument consists of 10 items, with a Likert scale answer key, ranging from 1 (not at all) to 5 (very much), which aims to assess the global life satisfaction of adolescents, aged 12 to 19 years. Examples of items: "I have everything I need," "I like my life," "I feel good the way I am." The internal consistency coefficient of the instrument was $\alpha=0.90$, and in this study it was $\alpha=0.96$ and the fit indices of the model were RMSEA $=0.05$; CFI $=$ 0.99 , and TLI $=0.98$.

Baptista Depression Scale for Children and Youth EBADEP-IJ (Baptista, 2018). The EBADEP-IJ is a self-report instrument composed of 27 items, with a Likert-type scale answer key, ranging from 0 (never/few times) to 2 (often/always), which aims to assess the occurrence of depression symptoms in children and adolescents, aged 8 to 18 years. Exploratory factor analysis, with main components and varimax rotation, indicated a two-factor solution, one with positive items, which are indicators of mental health (MHEALTH), and the other with negative items that assess the presence of depression symptoms (DEPRE). Examples of instrument items: "My days have 
been good" and "I feel without energy." The Cronbach's alpha coefficient for the instrument was 0.89 . In this research, the precision estimates were $\alpha=0.92$ and the fit indices were $\mathrm{RMSEA}=0.06 ; \mathrm{CFI}=0.94$, and TLI $=0.93$.

School Subjective Well-Being Scale - EBESE (Dias-Viana \& Noronha, 2021). Self-report instrument, composed of 27 items, distributed into two subscales. The first contains seven items that assess the student's satisfaction with the school. Ithas a 5-pointLikert scale answerkey, ranging from 1 (Totally Disagree) to 5 (Totally Agree). The second subscale measures the two affective factors of school SWB: PAS (10 items) and NAS (10 items). The items are characterized as adjectives that express various feelings and emotions experienced at school, answered on a 5-point Likert scale, ranging from 1 (Never) to 5 (Always). Considering the study objectives, only the affects at school subscale was used for this research. Examples of items: "Empowered," "Confident," "Motivated." The internal consistency coefficients were adequate for the PAS factors $(\alpha=0.87)$ and NAS factors $(\alpha=0.88)$. The scale model fit indices in this study were $\mathrm{RMSEA}=0.05 ; \mathrm{CFI}=0.92$, and TLI $=0.91$.

\section{Procedures}

Data collection. The sample was selected for convenience. Data collection was carried out in October 2018, a period with no school celebrations nor upcoming tests. Initially, authorization for data collection was requested from a public school located in the state of Ceará. The instruments were applied collectively, in the corresponding classes of the students and the instructions regarding the completion of the scales were read to the participants by the evaluator. The collection lasted one week and was carried out by a single researcher, who is a psychologist and has continued training in psychological assessment. The average time needed to answer the instruments was 40 minutes, in the following order of application: Sociodemographic and School Identification Questionnaire, EBESE, EBADEP-IJ, EGSV-A. The ethical procedures for conducting research with human beings were respected.

Data analysis. Pearson's correlation analysis $(r)$ was used to investigate the associations between the variables, using the raw scores obtained from the factors of EGSV-A, EBADEPIJ, and EBESE. The following criteria were adopted for interpretation of magnitudes: weak $(r<0.30)$, moderate $(0.30 \leq$ $r \leq 0.49)$, strong $(r \geq 0.50)$. Then, the VIF value was calculated for the diagnosis of multicollinearity between the variables.
We tested a model for investigating the effects of LS, PAS, and NAS on DEPRE and MHEALTH. Next, we tested PAS and NAS as mediating variables between LS (independent variables) and DEPRE and MHEALTH (dependent variables). The tested models were made through path analysis, with a Maximun Likelihood estimator and bootstrapping of 500 cases

The mediation model was tested following these steps: (a) life satisfaction (independent variable) should have direct effects on depression symptoms and mental health indicators (independent variables); and on factors of positive and negative affects at school (mediating variables); (b) PAS and NAS should have direct effects on DEPRE and MHEALTH; (c) the initial effect of LS on the independent variables should not be significant or be reduced, since the mediating variables were inserted in the model. We used $95 \%$ confidence interval for direct and indirect effects. The analyses were performed using the Statistical Package for the Social Sciences software, version 25 and Mplus 7.11.

\section{Ethical Considerations}

We followed the recommendations of Resolution No. 466/12 and Resolution No. 510/16 about the ethical specificities of research in Human and Social Sciences. The data used in this study were obtained from a project submitted to the Research Ethics Committee of Universidade São Francisco, approved with CAAE no. 97953218.2.0000.5514. Students aged under 18 years participated in the research with Free and Informed Consent Form (ICF) signed by one of the parents or legal guardians, in addition to the Free and Informed Assent Form (IAF) signed by the adolescent. Students who were aged 18 and 19 years signed the Informed Consent Form. It should be noted that the ethical aspects for research involving human beings were complied with. The participants were informed about the freedom to refuse to participate in the research, the guarantee of anonymity, and the confidentiality of the data.

\section{Results}

According to Table 1, DEPRE showed significant, negative, and strong correlations with LS and PAS, and positive and strong associations with NAS. MHEALTH indicators showed significant, positive, and strong correlations with LS and PAS, and moderate associations with NAS.

Table 1

Data Correlation Matrix

\begin{tabular}{|c|c|c|c|c|c|}
\hline Variable & $\mathrm{LS}$ & DEPRE & MHEALTH & PAS & NAS \\
\hline Life satisfaction (LS) & - & $-0.72 * *$ & $0.73 * *$ & $0.61 * *$ & $-0.43 * *$ \\
\hline Depression Symptoms (DEPRE) & $-0.72 * *$ & - & $-0.63 * *$ & $-0.54 * *$ & $0.54 * *$ \\
\hline Mental Health Indicators (MHEALTH) & $0.73 * *$ & $-0.63 * *$ & - & $0.68 * *$ & $-0.46^{* *}$ \\
\hline Positive Affects at School (PAS) & $0.61 * *$ & $-0.54 * *$ & $0.68^{* *}$ & - & $-0.43 * *$ \\
\hline Negative Affects at School (NAS) & $-0.43 * *$ & $0.54 * *$ & $-0.46 * *$ & $-0.43 * *$ & - \\
\hline
\end{tabular}

Note. ${ }^{* *} p<0.001$. 
In order to investigate the direct effect of the independent variables on depression symptoms and mental health indicators, we performed regression analysis using Structural Equation Modeling. We conducted diagnosis of multicollinearity between the variables. The VIF values obtained ranged from 1.27 to 1.65 , indicating that there are no exact or approximately exact linear relations. As shown in Figure 1, LS $(B$, non-standardized $=-0.24 ;$ Beta $=0.59)$ and NAS $(B$, non-standardized $=0.80 ;$ Beta $=0.44)$ were predictors of DEPRE (adjusted $R^{2}=0.65$ ).

As for the MHEALTH indicators, LS ( $B$, nonstandardized $=0.19 ;$ Beta $=0.50)$ and PAS ( $B$, nonstandardized $=0.16 ;$ Beta $=0.43$ ) were the predictor variables (adjusted $R^{2}=0.55$ ). Thus, if the LS indicators increased by 10 points, it would result in a decrease of 5.9 points in DEPRE and MHEALTH would increase by 5 points. In turn, an increase of 10 points in PAS and NAS would result in an increase of 4.3 points in MHEALTH indicators, and an increase of 4.4 points in DEPRE, respectively.
Considering the objective of investigating the mediating effect of affects at school (Vmed), the first step of the analysis was to identify the direct effect of LS on DEPRE and MHEALTH. The results indicated negative and significant effect $\left(B\right.$, non-standardized $={ }_{-} 0.33 ; p<0.001 ;$ Beta $\left.={ }_{-} 0.80\right)$ for DEPRE, and positive and significant effect ( $B$, nonstandardized $=0.28 ; p<0.001 ;$ Beta $=0.69$ ) for MHEALTH. Then, we tested two mediation models, inserting the PAS and NAS factors as mediating variables, for each of the outcomes (DEPRE and MHEALTH) (Figure 2).

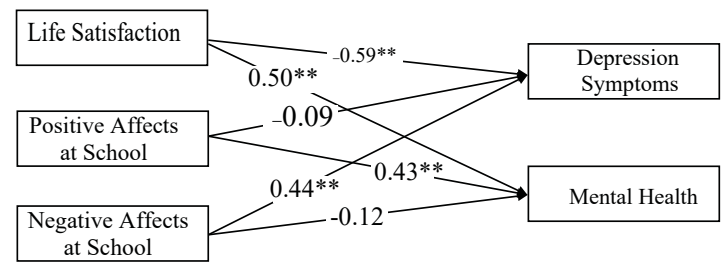

Figure 1. Path Analysis model of life satisfaction, positive and negative affects at school predicting depression symptoms and mental health indicators. Note. ${ }^{* *} p<0.001$.

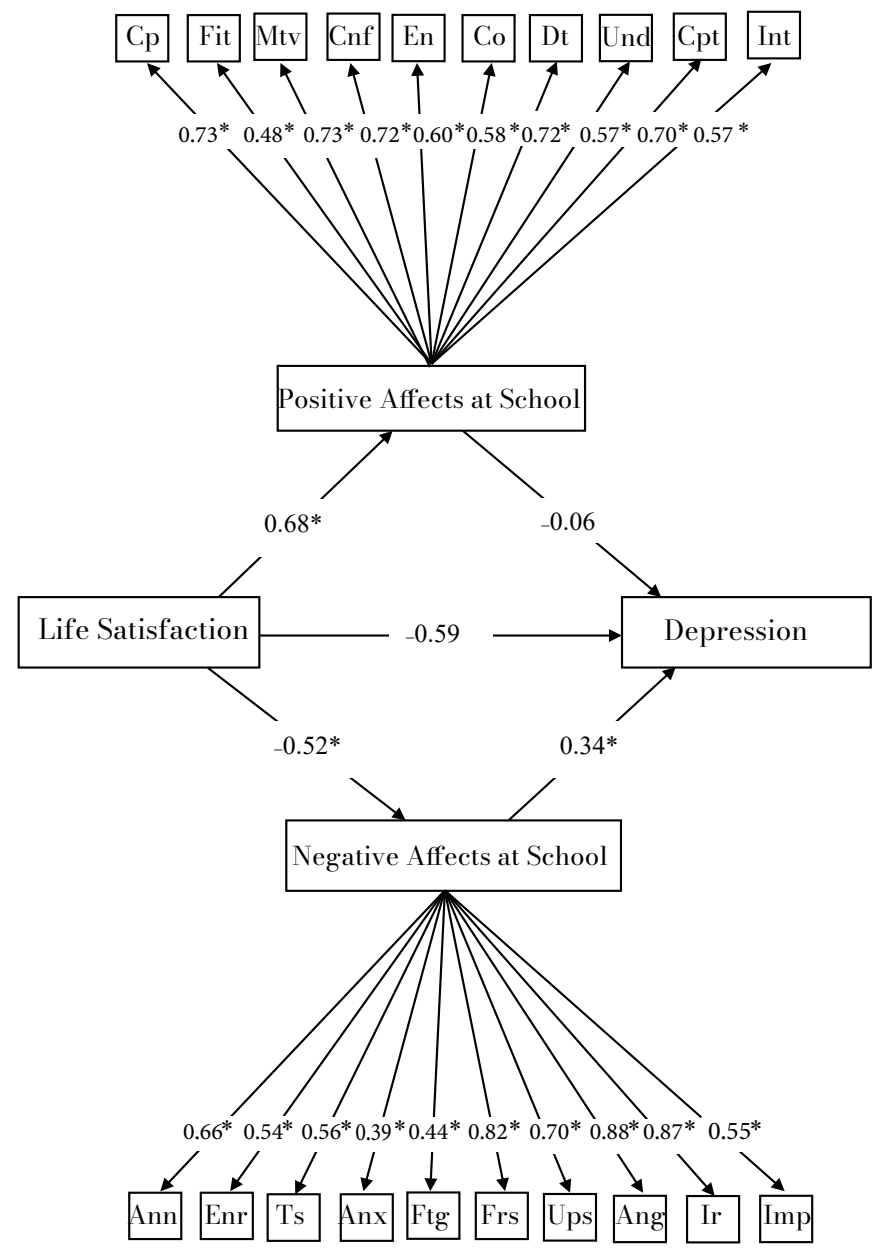

Figure 2. Mediation effect of positive and negative affects at school on the relation between life satisfaction and depression symptoms.

Note $. \mathrm{Cp}=$ capable; Fit = fit in; Mtv = motivated $\mathrm{Cnf}=$ confident $; \mathrm{En}=$ full of energy; $\mathrm{Co}=$ courageous; $\mathrm{DT}=$ determined; Und = understood; $\mathrm{Cpt}=$ competent; Int = interested; Ann = annoyed; Enr = enraged; Ts = tense; Anx = anxious; Ftg = fatigued; Frs = furious; Ups = upset; Ang $=$ angry; $\operatorname{Ir}=$ irritated; Imp $=$ impatient. ${ }^{*} p<0.05$. 
As shown in Figure 2, for the depression symptoms outcome, only NAS mediated the relation between the variables, being negatively associated with LS and positively associated with DEPRE. As for the MHEALTH outcome, PAS and NAS mediated the relation between the variables (Figure 3 ). In both models, we observed a reduction in direct effects (Table 2).
The data showed that $23.37 \%$ of the indirect effect between IV and DV was explained by the NASs, and that, after inserting the Vmed, the direct effect between LS and DEPRE was reduced by $26.25 \%$. As for MHEALTH, only the PASs acted as mediators, in that $28.16 \%$ of the indirect effect between IV and DV was explained by the positive affect at the school setting, and, after inserting the PAS, the direct effect between LS and MHEALTH was reduced by $26 \%$.

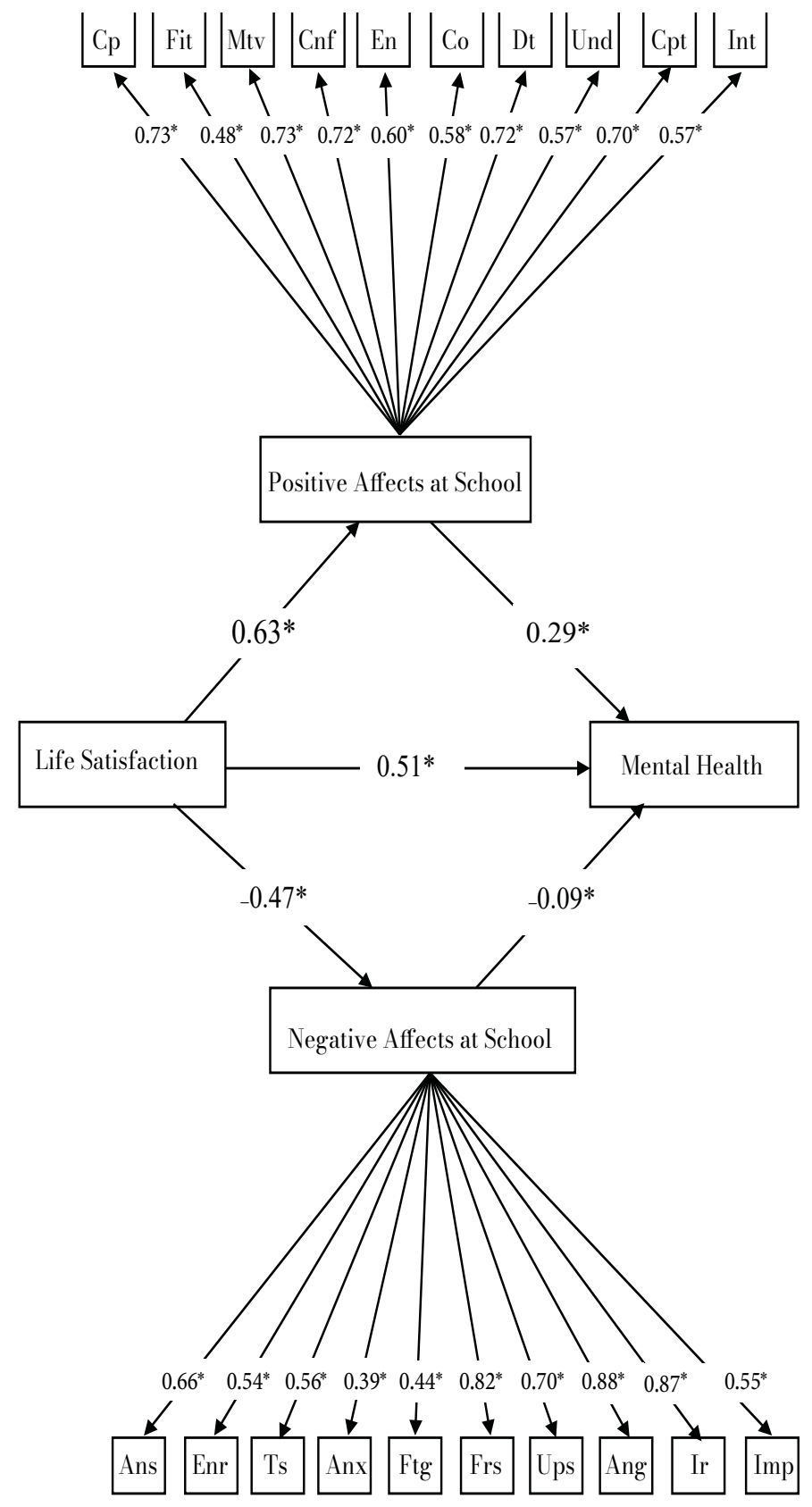

Figure 3. Effect of mediation between positive and negative affects at school on the relationship between satisfaction with life and mental health. Note. $\mathrm{Cp}=$ capable; Fit = fit in; $\mathrm{Mtv}=$ motivated $\mathrm{Cnf}=$ confident $\mathrm{En}=$ full of energy; $\mathrm{Co}=$ courageous; $\mathrm{DT}=$ determined; Und = understood; $\mathrm{Cpt}=$ competent; Int $=$ interested; Ann = annoyed; Enr = enraged; Ts = tense; Anx = anxious; Ftg $=$ fatigued; Frs = furious; Ups = upset; Ang = angry; Ir $=$ irritated; Imp $=$ impatient. ${ }^{*} p<0.05$. 
Table 2

Standardized Effect Coefficients of the Mediation Models Investigated

\begin{tabular}{|c|c|c|c|}
\hline Model & $\begin{array}{c}\text { Direct effect } \\
\text { without Vmed }\end{array}$ & $\begin{array}{c}\text { Direct Effect with } \\
\text { Vmed }\end{array}$ & Indirect Effect \\
\hline \multicolumn{4}{|l|}{ Model 1: Depression Symptoms } \\
\hline \multicolumn{4}{|l|}{ Vmed: Positive Affects at School } \\
\hline \multicolumn{4}{|l|}{ Life satisfaction $\rightarrow$ Positive Affects at School } \\
\hline Positive Affects at School $\rightarrow$ Depression Symptoms & $-0.80 * *$ & $-0.59 * *$ & -0.04 \\
\hline \multicolumn{4}{|l|}{ Life satisfaction $\rightarrow$ Depression symptoms } \\
\hline \multicolumn{4}{|l|}{ Vmed: Negative Affects at School } \\
\hline \multicolumn{4}{|l|}{ Life satisfaction $\rightarrow$ Negative Affects at School } \\
\hline Negative Affects at School $\rightarrow$ Depression Symptoms & $-0.80^{* *}$ & $-0.59 * *$ & $-0.17 * *$ \\
\hline \multicolumn{4}{|l|}{ Life satisfaction $\rightarrow$ Depression symptoms } \\
\hline \multicolumn{4}{|l|}{ Model 2: Mental Health Indicators } \\
\hline \multicolumn{4}{|l|}{ Vmed: Positive Affects at School } \\
\hline \multicolumn{4}{|l|}{ Life satisfaction $\rightarrow$ Positive Affects at School } \\
\hline Positive Affects at School $\rightarrow$ Depression Symptoms & $0.69 * *$ & $0.51 * *$ & $0.20 * *$ \\
\hline \multicolumn{4}{|l|}{ Life satisfaction $\rightarrow$ Depression symptoms } \\
\hline \multicolumn{4}{|l|}{ Vmed: Negative Affects at School } \\
\hline \multicolumn{4}{|l|}{ Life satisfaction $\rightarrow$ Negative Affects at School } \\
\hline Negative Affects at School $\rightarrow$ Depression Symptoms & $0.69 * *$ & $0.51 * *$ & 0.05 \\
\hline Life satisfaction $\rightarrow$ Depression symptoms & & & \\
\hline
\end{tabular}

\section{Discussion}

The present study aimed to investigate the relations between the life satisfaction, positive affects at school, and negative affects at school variables and depressive symptoms and mental health indicators in adolescents. Moreover, we sought to evaluate the mediating role of positive and negative affects at school in the relation between life satisfaction and depression symptoms and mental health indicators. The results support the mediation models.

The results obtained showed that youth LS is negatively associated with depression symptoms and positively associated with mental health indicators. These results corroborate the studies of Lin and Yi (2019) and Morales-Vives and Dueñas (2018), in which negative relations were found between life satisfaction and depression symptoms, and positive relation with mental health. Life satisfaction is a multidimensional construct, in which the assessment that adolescents make of their lives depends on satisfactory and stressful experiences in different contexts such as family, leisure opportunities, friendship relationships, and school (Huebner, 2004). Thus, the better the assessment that adolescents make of their lives, the less vulnerable they are to depressed mood and negative affect, which is characteristic of depression (APA, 2014). Accordingly, this emphasizes the importance of fostering this component of SWB as a strategy for preventing depression symptoms and promoting mental health in adolescents. Given the increase in depression indicators and in the impairment of youth mental health (WHO, 2017), providing pleasurable life experiences in these contexts is a promising intervention strategy.

In addition to investigating the associations between life satisfaction and youth mental health aspects, the present study sought to enhance the complexity of the model, by testing direct and indirect effects, with the insertion of positive and negative affects at school. By analyzing the results of this study, NAS mediated the relation between LS and DEPRE. Thus, the lower the adolescents' assessment of their lives, the more they are susceptible to feelings of incapacity, anxiety, and annoyance at school, and the more vulnerable to depression symptoms, manifested through feelings of guilt, loneliness, and even suicidal ideation.

In addition, PAS and NAS mediated the relation of LS and the positive indicators of healthy psychological functioning. In this sense, the better the assessment that adolescents make of their lives, the more they feel confident, determined and capable in their school development, and the more present will be feelings that protect mental health, such as an optimistic view of oneself, perception of social support, and beliefs in a good future. Thus, regarding the hypothesis related to mediation $(\mathrm{H} 2)$, it was partially corroborated. 
According to the DSM-5 (APA, 2014), neuroticism traits, such as anxiety, fear and loneliness, are the main risk factors for triggering psychopathologies, especially mood disorders, characterized by emotional changes and greater susceptibility to negative affectivity. In contrast, positive emotionality at school is preponderant for youth mental health. Recent studies on children and youth mental health indicate a theoretical model of children and youth psychopathology composed of two independent factors (orthogonal) - psychopathology (negative affectivity) and mental health (positive affectivity) - as observed in the theoretical model of the Strengths and Difficulties Questionnaire (Caci et al., 2015) and in the research of Baptista et al. (2016) testing an orthogonal model between these factors. Thus, the differential functioning of the PASs and NASs in the investigated outcomes corroborates the theoretical conception of these factors, since the affects at school are not opposite poles of the same dimension, but independent variables, where the adolescent can experience both positive and negative emotionality in the school context (Dias-Viana \& Noronha, 2021; Diener et al., 2017).

Considering the results, it was found that this study advances in relation to the literature because it presents a model of complex relations for depression symptoms in adolescence, showing the importance of the affective components of the student's school well-being. In summary, the better the adolescent's assessment of their life, the more present are the positive affects at school, and the lower the levels of displeasure in the school setting, the less susceptible the adolescent will be to the development of depression symptoms. Although life satisfaction is a global measure, not enabling us to determine how much each context contributes to the prevention of depression symptoms in adolescence, this study shows that around $1 / 4$ of the effect of LS on depression symptoms is explained by affects at school. It is observed the importance of school managers and faculty in promoting feelings of capacity and motivation related to learning, in addition to feelings of belonging to the school community, as a strategy for the prevention of depression symptoms in adolescence.

As described, the school participating in this research has good educational indicators and good physical and pedagogical structure. However, in a previous study, Dias-Viana \& Noronha (2021) found that fatigue and lack of understanding are the main feelings experienced by students at this school. Considering the period of adolescence, feeling tired is common at this stage of human development, taking into account the physical and biological changes. Moreover, fatigue may also be related to aspects of the student's social reality and the school's curricular structure. Because it is a "model" school of the public school system, it has a differentiated curriculum, with a greater number of extracurricular activities, attracting students from neighboring municipalities, with long homeschool commutes. Furthermore, the students' perception of social support during adolescence is associated with their classmates and teachers, showing the importance of fostering healthy relationships between these groups for the promotion of positive affects at school (Pössel et al., 2018).
From a practical perspective, the school, as a context of adolescent development, becomes a fruitful setting for implementing preventive programs related to mental health. Since the school is committed to the full development of students, it is recommended the inclusion of content in the school curricula and the implementation of interventions that promote a positive schooling experience, focusing on the students' well-being and mental health $(\mathrm{Au} \&$ Kennedy, 2018). However, most school-based prevention programs for the prevention of depression focus on students' global individual characteristics, not including contextual characteristics (Bernaras et al., 2019). Based on the results, when designing interventions geared toward adolescents with complaints related to depression and also from a mental health promotion perspective, it is recommended the use of strategies that strengthen the bonds between students, with their teachers, that foster the students' beliefs of capability and motivation as to their learning.

The main contribution of this research is the evidence of the student's affectivity in the school setting as a protection or risk variable for youth mental health concerning depression symptoms. Some limitations of the study should be considered when interpreting the results. The use of a convenience sample, only with students from a Brazilian city, limits the generalization of the results. Another factor to be considered is the use of self-report measures, which may favor response biases, such as social desirability and acquiescence, making the participants' answers not exactly consistent with reality. For future studies, it is suggested the use of other sources of information, such as teacher reports, parent reports, and objective school data (for example, suspensions due to violent behavior), and that studies should be conducted with adolescents from different locations, for greater variability of responses. In addition, longitudinal studies monitoring the students' affectivity in the context of test situations, recreational situations, and during celebration periods would assist in better understanding the phenomenon.

\section{References}

American Psychiatric Association. (2014). Diagnostic and statistical manual of mental disorders: DSM-5 (5th ed.). Washington, DC: Author. doi: 10.1176/appi. books. 9780890425596

Au, W. C. C., \& Kennedy, K. J. (2018). A positive education program to promote wellbeing in schools: A case study from a Hong Kong school. Higher Education Studies, 8(4), 9-22. doi: 10.5539/hes.v8n4p9

Baptista, M. N. (2018). Manual da Escala Baptista de Depressão: Versão infanto-juvenil [Baptist Depression Scale Manual for Children and Youth]. São Paulo, SP: Hogrefe. 
Baptista, M. N., Hauck Filho, N., \& Cardoso, C. (2016). Depressão e bem-estar subjetivo em crianças e adolescentes: Teste de modelos teóricos [Depression and subject well-being in children and adolescents: Testing theoretical model]. Psico, 47(4), 259-267. doi:10.15448/1980-8623.2016.4.23012

Bernaras, E., Jaureguizar, J., \& Garaigordobil, M. (2019). Child and adolescent depression: A review of theories, evaluation instruments, prevention programs, and treatments. Frontiers in Psychology, 10, 543. doi:10.3389/fpsyg.2019.00543

Caci, H., Morin, A. J. S., \& Tran, A. (2015). Investigation of a bifator model of the Strengths and Difficulties Questionnaire. European Child \& Adolescent Psychiatry, 24(10), 1291-1301. doi:10.1007/s00787-015-0679-3

Dias-Viana, J. L., \& Noronha, A. P. P. (2021). School Subjective Well-Being Scale (EBESE): Development and validation of an education assessment measure. Ciencias Psicológicas, 15(1), e2349. doi:10.22235/cp.v15i1.2349

Díaz-García, A., González-Robles, A., Mor, S., Mira, A., Quero, S., García-Palacios, A., ... \& Botella, C. (2020). Positive and Negative Affect Schedule (PANAS): Psychometric properties of the online Spanish version in a clinical sample with emotional disorders. $B M C$ Psychiatry, 20(1), 56. doi:10.1186/s12888-020-2472-1

Diener, E., Heintzelman, S. J., Kushlev, K., Tay, L., Wirtz, D., Lutes, L. D., \& Oishi, S. (2017). Findings all psychologists should know from the new science on subjective well-being. Canadian Psychology, 58(2), 87-104. doi:10.1037/cap0000063

Gigantesco,A., Fagnani, C., Toccaceli, V., Stazi, M.A., Lucidi, F., Violani, C., \& Picardi, A. (2019). The relationship between satisfaction with life and depression symptoms by gender. Frontiers in Psychiatry, 10, 419. doi:10.3389/fpsyt.2019.00419

Huebner, E. S. (2004). Research on assessment of life satisfaction on children and adolescents. Social Indicators Research, 66, 3-33. doi:10.1023/B:SOCI.0000007497.57754.e3

Instituto Brasileiro de Geografia e Estatística. (2016). Pesquisa nacional de saúde do escolar: 2015 [Student's health national research: 2015]. Rio de Janeiro, RJ: IBGE. Retrieved from https://biblioteca.ibge.gov.br/ visualizacao/livros/liv97870.pdf

Lin, W.-H., \& Yi, C.-C. (2019). The effect of family cohesion and life satisfaction during adolescence on later adolescent outcomes: A prospective study. Youth \& Society, 51(5), 680-706. doi:10.1177/0044118x17704865
Lombardo, P., Jones, W., Wang, L., Shen, X., \& Goldner, E. M. (2018). The fundamental association between mental health and life satisfaction: Results from successive waves of a canadian national survey. BMC Public Health, 18(1), 342. doi:10.1186/s12889-018-5235-x

Lu, W. (2019). Adolescent depression: National trends, risk factors, and healthcare disparities. American Journal of Health Behavior, 43(1), 181-194. doi:10.5993/ajhb.43.1.15

Morales-Vives, F., \& Dueñas, J. M. (2018). Predicting suicidal ideation in adolescent boys and girls: The role of psychological maturity, personality traits, depression and life satisfaction. The Spanish Journal of Psychology, 21, E10. doi:10.1017/sjp.2018.12

Organization for Economic Co-operation and Development. (2017). PISA 2015 Results (Volume III): Student's wellbeing. doi: 10.1787/19963777

Pekrun, R. (2017). Emotion and achievement during adolescence. Child Development Perspectives, 11(3), 215-221. doi:10.1111/cdep.12237

Pössel, P., Burton, S. M., Cauley, B., Sawyer, M. G., Spence, S. H., \& Sheffield, J. (2018). Associations between social support from family, friends, and teachers and depressive symptoms in adolescents. Journal of Youth and Adolescence, 47(2), 398-412. doi:10.1007/s10964-017-0712-6

Robina-Ramírez, R., Medina Merodio, J. A., \& McCallum, S. (2020). What role do emotions play in transforming students' environmental behaviour at school? Journal of Cleaner Production, 258, 120638. doi:10.1016/j.jclepro.2020.120638

Segabinazi, J. D., Zortea, M., \& Giacomoni, C. H. (2014). Avaliação de bem-estar subjetivo em adolescentes [Wellbeing assessment in adolescents]. In C. S. Hutz (Org.), Avaliação em psicologia positiva [Assessment in positive psychology] (pp. 69-84). Porto Alegre, RS: Artmed.

World Health Organization. (2017). Depression and other common mental disorders: Global health estimates. Geneva, Switzerland: Author. Retrieved from https://apps.who.int/iris/handle/10665/254610

Yang, X., Lau, J. T. F., \& Lau, M. C. M. (2018). Predictors of remission from probable depression among Hong Kong adolescents - a large-scale longitudinal study. Journal of Affective Disorders, 229, 491-497. doi:10.1016/j.jad.2017.12.080

Zhu, X., \& Shek, D. T. L. (2020). The influence of adolescent problem behaviors on life satisfaction: Parent-child subsystem qualities as mediators. Child Indicators Research, 13, 1767-1789. doi:10.1007/s12187-020-09719-7 
João Lucas Dias-Viana is a Ph.D. candidate of the Universidade São Francisco, Campinas-SP, Brazil.

Ana Paula Porto Noronha is a Professor of the Universidade São Francisco, Campinas-SP, Brazil.

Authors' Contribution:

All authors made substantial contributions to the conception and design of this study, to data analysis and interpretation, and to the manuscript revision and approval of the final version. All the authors assume public responsability for content of the manuscript.

Associate editor:

Adriana Martins Saur

Received: Apr. 13, 2021

1st Revision: Jul. 09, 2021

2nd Revision: Aug. 29, 2021

3rd Revision: Sep. 10, 2021

Approved: Sep. 24, 2021

How to cite this article:

Dias-Viana, J. L., \& Noronha, A. P. P. (2022). Life satisfaction, affects at school and depressive symptoms among adolescents. Paidéia (Ribeirão Preto), 32, e3203. doi:https://doi.org/10.1590/1982-4327e3203 